American Journal of Pharmaceutical Education 2020; 84 (10) Article 8136.

\title{
COMMENTARY
}

\section{Years of Rampant Expansion Have Imposed Darwinian Survival-of-the-Fittest Conditions on US Pharmacy Schools}

\author{
Daniel L. Brown, PharmD \\ South University School of Pharmacy, Columbia, South Carolina \\ Submitted May 5, 2020; accepted June 22, 2020; published October 2020.
}

\begin{abstract}
The number of applicants to US pharmacy schools has been declining since 2013, leading to a national enrollment crisis. Enrollment challenges threaten the viability of many pharmacy programs. Some schools are better equipped than others to confront the risk of having to downsize or close, creating survival-of-the-fittest conditions. Four potential risk factors have been identified based on how applicants might perceive the comparable value of respective programs. Schools with lower risk are public, established before 2000, located within an academic health center, and traditional (ie, four-year) programs.

The Academy cannot sustain more than 140 schools much longer. Market forces are establishing a new equilibrium between the number of graduates and the availability of pharmacist jobs. As more jobs become available, more applicants will apply. Until then, the fittest Doctor of Pharmacy programs will thrive, while others might have to downsize to survive, and the weakest will be at risk of extinction.
\end{abstract}

Keywords: academic expansion, pharmacy academy, enrollment, survival of the fittest, education value

This is a story about what can happen when academia expands beyond the capacity of the market it serves. As the academic story unfolded in the early 2000 s, it revealed colleges and universities that were eager to take advantage of the popularity of pharmacy as a career field. Prompted by an abundance of applicants, the academy embarked on a period of growth so expansive that it overwhelmed a thriving pharmacist job market by doubling the annual number of graduates in less than 20 years. ${ }^{1}$ There were about 80 schools of pharmacy in the United States in 2000, now there are 143. Existing Doctor of Pharmacy (PharmD) programs also contributed significantly to the expansion as the average class size increased almost 30\% from 2001 to $2012 .^{2}$ The National Center for Health Workforce Analysis now projects an oversupply of 19,000 to 51,000 pharmacists in the United States by $2030 .^{3}$

Indeed, pharmacy education was a highly lucrative venture for schools and universities back in 2000. To academic institutions in search of new revenue streams, pharmacy was the goose that laid golden eggs. But that has changed. By 2014, the powerful engine of academic

Corresponding Author: Daniel L. Brown. Davenport, FL.

Email: pharmdan22@yahoo.com

Note: At the time of manuscript submission and acceptance, the author was affiliated with South University School of Pharmacy. He retired from that institution in September 2020. growth had begun to decelerate, and it has since ground to a halt. For the first time since 2004, no new schools are scheduled to open in 2020. Only one new program remains in the academic pipeline, the University of California at Irvine, which will become California's 15th school of pharmacy.

This commentary is the third in a series of articles calling attention to the hazards of uncontrolled academic growth. The first, written in 2010, cautioned that academic expansion was occurring too rapidly, at a pace that would be deleterious to the profession. ${ }^{4}$ The second, written three years later, warned that continued expansion would saturate the pharmacist job market and create a joblessness crisis for new graduates. ${ }^{1}$ This final report explores the aftereffects of a weakened job market, which is causing fewer students to view pharmacy as an attractive career option. It describes the survival-of-the-fittest dynamics that pharmacy programs now face amid a shrinking applicant pool. For some schools, the challenge of achieving enrollment goals has become a fight for survival. As Darwinism specifies, the fittest will survive; others might not be as fortunate.

\section{Evolution of an Enrollment Crisis}

Unprecedented academic expansion left in its wake a new era in which the Academy is facing a severe enrollment crisis. The number of verified Pharmacy College 


\section{American Journal of Pharmaceutical Education 2020; 84 (10) Article 8136.}

Application Service (PharmCAS) applicants has decreased every year since 2013 when it peaked at $17,617 . .^{5}$ The number had fallen to 15,335 by 2019 , and based on a June 2020 PharmCAS update, is poised to fall another $11.0 \%$ to about 14,000 during the $2019-2020$ admission cycle, which constitutes a drop of $20 \%$ since $2017.5,6$ The average enrollment of an entering class has dropped annually since 2012, from 124 to $102 .^{2}$ According to an American Association of Colleges of Pharmacy (AACP) survey completed in March 2020, of the 134 respondent schools, $62 \%$ reported not being able to fill the entering class in 2019, with a mean of 15.6 unfilled seats. ${ }^{7}$ The Academy has reached an ominous point of critical mass, in which the number of applicants is barely equal to the number of available seats. ${ }^{2,5}$

Pharmacy education used to be an excellent value among health profession options. Tuition costs were reasonable and the return on investment was substantial, in terms of a guaranteed high-paying job upon graduation. That is no longer the case. In 2004, the combined annual tuition and fees for in-state public and private pharmacy schools averaged \$10,297 and \$21,374, respectively. ${ }^{8}$ By 2019 , those mean costs had risen to $\$ 25,012$ and $\$ 41,602 .{ }^{8}$ Increased tuition costs have translated into ballooning student debt. According to the 2019 AACP Graduating Pharmacy Student Survey, mean student loan debt at graduation was $\$ 144,083$ and $\$ 198,560$ for public and private school graduates, respectively. ${ }^{9}$ These debt totals represent an increase of almost $70 \%$ over the last 10 years. ${ }^{9}$

Gone are the days of guaranteed full-time, highpaying positions for graduates straight out of pharmacy school. Many pharmacy graduates are faced with accepting part-time or per diem positions, reduced salaries, difficult working conditions, undesirable locations, and/or unemployment. ${ }^{10}$ It is no wonder that fewer students are choosing pharmacy as a career. The value is not what it used to be.

Some pharmacy leaders downplay the role of academic expansion as the primary cause of diminishing enrollment based on the premise that an unstable economy and fewer high school graduates are precipitating factors. ${ }^{11}$ However, such inferences are contradicted by the growing number of applicants to some other health profession programs. From 2002 to 2018, enrollment in medical schools increased $31 \%{ }^{12}$ Total enrollment of the first-year classes in colleges of osteopathic medicine grew $27 \%$ from 2013 to $2018 .{ }^{13}$

\section{Ramifications for Programs and Faculty Members}

Years of expansion enabled PharmD programs to reap the benefits of increased tuition revenue, which provided funding for new buildings, enhanced facilities, additional personnel, and surplus income for parent institutions. But times of affluence have given way to hardship. Many schools are no longer able to meet their enrollment goals, leading to reduced tuition revenue and budget shortfalls. The prospects for being able to sustain more than 140 programs beyond 2020 are slim. Most programs will have to downsize as enrollment declines further; others will be forced to close.

Many current faculty members occupy positions within pharmacy schools that would not exist had it not been for years of academic expansion. Between 2006 and 2018 , the number of full-time pharmacy faculty members rose $60 \%$, from 4,121 to 6,574 ; however, in 2019 , the number of faculty members dropped slightly. ${ }^{14}$ The emerging period of school downsizing or closing will produce a restrictive faculty job market. Some will join the ranks of the unemployed and those aspiring to a career in academia will find it difficult to secure an entry-level position. Opportunities for advancement into leadership positions will be less prevalent than in years past.

The pharmacy enrollment crisis is a widespread national phenomenon, but not all schools are affected to the same degree. The risks incurred by some programs are mitigated by the greater value that they offer to potential applicants. Ford explored the value of pharmacy education from the perspective of a comparative value index that is derived from the cost of tuition and pass rates on the North American Pharmacist Licensure Examination (NAPLEX). ${ }^{15}$ Williams and colleagues compared mean NAPLEX pass rates between various categories of schools from 2014 through $2016 .{ }^{16}$ These studies distinguished four risk factors based on the potential for perceived value by prospective applicants.

First, public schools have less risk than private schools. The mean cost of tuition and fees for public schools (in state) is roughly half that of private schools. ${ }^{8}$ Furthermore, graduates of public schools perform significantly better on the NAPLEX. ${ }^{17}$ Williams and colleagues reported higher NAPLEX pass rates for public schools than private $(p<.001) .{ }^{16}$ Figure 1 illustrates that public schools achieved a higher mean NAPLEX pass rate every year from 2008 through 2019, and the disparity between the two groups widened markedly after the exam was modified in 2016. ${ }^{17}$ According to Ford's tuition: licensure index, the difference in value is statistically significant $(p<.001) .^{15}$

Second, schools located within an academic medical center have less risk. Williams and colleagues found that graduates of schools within academic medical centers performed better on the NAPLEX than other PharmD graduates $\quad(p<.001) .{ }^{16}$ Bauman and colleagues 


\section{American Journal of Pharmaceutical Education 2020; 84 (10) Article 8136.}

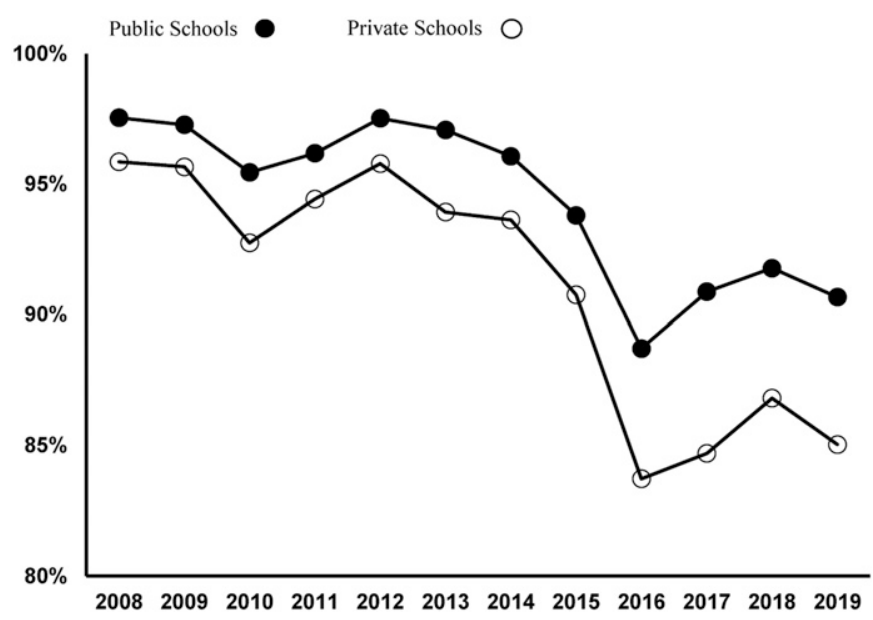

Figure 1. Mean NAPLEX First-time Pass Rates for Public and Private Schools (2008-2019)

articulated the attributes of schools associated with academic health centers, such as advanced research in scientific discovery, outstanding clinical resources, and abundant opportunities for interdisciplinary education. ${ }^{18}$ DiPiro expressed concern that clinical faculty members at schools that have only a nominal affiliation with a health center might not be as directly involved in the provision of patient care. ${ }^{19}$ He suggested that quality pharmacy education should include functional integration rather than mere affiliation with an academic health center.

Third, schools that opened before 2000 have less risk than those that opened after 2000. Legacy schools benefit from the advantages of being well established, having a respected reputation, and drawing support from an active alumni base. Williams and colleagues found significantly higher NAPLEX pass rates for pre-2000 schools $(p=.001) .{ }^{16}$ The 2019 NAPLEX pass rates for pre-2000 schools were twice as likely to exceed $95 \%$, whereas post2000 schools were eight times more likely to score below $80 \%$ (Table 1). ${ }^{17}$

Fourth, traditional (four-year) programs have less risk than accelerated (three-year) programs. Williams and colleagues found significantly higher 2016 NAPLEX pass rates for four-year programs than three-year programs $(p=.01) .{ }^{16}$ In 2019 , more than a third of the accelerated programs had a mean NAPLEX pass rate below $80 \%$ (Table 1). ${ }^{17}$ The curricular compression that results from condensing a PharmD program into three years can place undue strain on both faculty members and students, and undermine the success of students who find it difficult to endure the accelerated pace.

The nature and magnitude of enrollment-related risks are vastly different among programs. Some programs are better equipped for survival than others, and each must address such challenges from their own unique
Table 1. Breakdown of 2019 NAPLEX Pass Rates for US Pharmacy Schools by Category ${ }^{17}$

\begin{tabular}{|c|c|c|}
\hline School Category & $\begin{array}{c}\text { School Pass } \\
\text { Rate } \geq 95 \\
(\% \text { of } n)\end{array}$ & $\begin{array}{c}\text { School Pass } \\
\text { Rate }<\mathbf{8 0} \\
(\% \text { of } \mathbf{n}) \\
\end{array}$ \\
\hline All schools $(n=135)$ & $24(18)^{\mathrm{a}}$ & $26(19)^{\mathrm{a}}$ \\
\hline Public schools $(n=66)$ & $16(24)$ & $4(6)$ \\
\hline Private schools $(n=69)$ & $8(12)$ & $22(32)$ \\
\hline Pre-2000 $(n=81)$ & $18(22)$ & $4(5)$ \\
\hline Post-2000 $(n=54)$ & $6(11)$ & $22(41)$ \\
\hline 4-year $(n=120)$ & $23(19)$ & $20(17)$ \\
\hline 3 -year $^{b}(n=15)$ & $1(7)$ & $6(40)$ \\
\hline
\end{tabular}

Abbreviations: NAPLEX $=$ North American Pharmacist Licensure Examination

${ }^{a}$ In 2012, of the 109 schools that participated in the NAPLEX, 76\% had a mean pass rate $\geq 95 \%$. No school had a mean pass rate $<80 \%$ ${ }^{\mathrm{b}}$ Of the 19 accelerated programs, three had not yet graduated a class and one had recently converted from a traditional to an accelerated program, leaving a total of 15 accelerated programs with 2019 NAPLEX results

perspective. It is difficult to predict the extent to which the COVID-19 pandemic might affect the future of some pharmacy schools. Higher education has been significantly impacted by the global economic shutdown and the abrupt shift from live, on-campus teaching to remote virtual instruction. Unforeseen fiscal challenges associated with the pandemic are likely to play a role, either directly or indirectly, in the viability of some pharmacy schools.

\section{Practical Survival Strategies}

Contrary to popular belief, survival-of-the-fittest conditions need not spark competition or produce winners and losers. The objective is not to win by defeating an opponent, but to stay in the game and survive. Programs would do well to collaborate in developing effective strategies and best practices by observing and learning from each other.

Schools can adapt acutely to smaller class sizes by adjusting resources and reducing expenses to compensate for decreases in revenue. ${ }^{10}$ Disciplined retrenchment efforts can reposition programs for a stable and prosperous future. However, the best short-term solution to the enrollment crisis directly addresses the supply side of the equation, ie, attract more applicants. Practical steps can be taken to sustain enrollment by strategically expanding the applicant pool. Private schools might find it prudent to scale back tuition or offer needs-based scholarships to offset tuition costs. ${ }^{20}$ Targeted outreach activities directed toward local high schools and colleges can be effective at attracting additional applicants, especially if conducted personally by faculty representatives. Likewise, guided academic pathways and affiliation 


\section{American Journal of Pharmaceutical Education 2020; 84 (10) Article 8136.}

agreements can establish academic pipelines by which to produce a steady flow of future applicants. ${ }^{20}$ The entire admissions process, including interviews, should be strategically designed to establish positive connections with applicants by ensuring a user-friendly experience, a welcoming environment, and regular communication with multiple touchpoints. ${ }^{21}$ It might also be helpful to remove eligibility barriers from admission standards that inadvertently block qualified applicants, such as requiring prospective students to have completed a specific prerequisite course that is not essential or to have taken the Pharmacy College Admission Test (PCAT). ${ }^{20}$ On a broader scale, pharmacy organizations are attempting to attract students to pharmacy by enhancing the public perception of pharmacists. ${ }^{20}$ The "Pharmacy is Right for Me" campaign has been successfully launched, but it remains to be seen whether national marketing efforts will significantly increase the number of applicants. ${ }^{22}$

Some schools might be tempted to meet enrollment targets by lowering admission standards, but that is an illadvised strategy. Admitting weaker candidates can subject programs to a different crisis, one of poor academic performance, manifested by increased student attrition and subpar NAPLEX pass rates. Programs that relax admission requirements are likely to incur even greater risk in the long run unless they employ comprehensive student success strategies that are designed to identify struggling students and proactively intervene to mitigate their academic deficiencies.

The best long-term solution to the enrollment crisis addresses the demand side of the equation and can be summed up in one word: jobs. If the pharmacist job market returns, it would follow that a robust applicant pool will return in kind. The entire profession must make job creation its number one priority, with a focus on financially sustainable, patient-care-oriented positions for all practice settings. ${ }^{10,11}$ Clinical faculty members should be fully engaged in creating and justifying new fiscally sound practice models, and then integrate the training of such entrepreneurial skills into their pharmacy practice experiences.

Pharmacy does not have the luxury of waiting for provider status to be granted. It will not be a panacea that instantly produces thousands of pharmacist jobs as if flipping a switch. Provider status will lead to job creation only after innovative, pioneering practitioners design and implement functional practice models that can be readily justified and reproduced. Provider status for pharmacists is akin to the homestead acts of the 19th century that afforded settlers the opportunity to own and develop land. Homestead acts opened doors of opportunity, but it was up to individual settlers to stake a claim, cultivate the land, and build a home.

Imbalance within a system induces powerful natural forces that drive the system back into a state of equilibrium. Supply and demand market forces are already at play in pharmacy to correct the imbalance between the production of graduates and the availability of jobs. As equilibrium is being reestablished, the Academy will endure a period of retrenchment, characterized by program downsizing and some school (or satellite) closures. The fittest programs will thrive, lesser programs will downsize to survive, and the weakest programs will face extinction. Once equilibrium is restored, it will be up to the academic leaders of the future to maintain it.

\section{REFERENCES}

1. Brown DL. A looming joblessness crisis for new pharmacy graduates and the implications it holds for the academy. Am J Pharm Educ. 2013;77(5):Article 90.

2. American Association of Colleges of Pharmacy. Fall 2019 Profile of Pharmacy Students Enrollments. https:/www.aacp.org/sites/ default/files/2020-05/fall-2019-pps-enrollments.pdf. Accessed September 29, 2020.

3. The U.S. Health Resources and Services Administration, National Center for Health Workforce Analysis. Allied Health Workforce Projections, 2016-2030: Pharmacists. https://bhw.hrsa.gov/sites/ default/files/bhw/nchwa/projections/pharmacists-2016-2030.pdf Accessed September 29, 2020.

4. Brown D. From shortage to surplus: the hazards of uncontrolled academic growth. Am J Pharm Educ. 2010;74(10): Article 185.

5. American Association of Colleges of Pharmacy. 2018-2019 PharmCAS Applicant Data Report. https://connect.aacp.org/ HigherLogic/System/DownloadDocumentFile.ashx?

DocumentFileKey $=6 f d 0 b f 77-20 d 6-8 b d 0-e a 8 f-802291427396$. Accessed September 29, 2020.

6. American Association of Colleges of Pharmacy. PharmCAS Volume Update: June 2, 2020. https://connect.aacp.org/ viewdocument/pharmcas-volume-update-jun-2020-1?CommunityKey= aeb59d45-0cea-44ef-8060-29508a5725eb\&tab=librarydocuments. Accessed September 29, 2020.

7. American Association of Colleges of Pharmacy. AACP PharmD Seats Report. https://higherlogicdownload.s3-external1.amazonaws. com/AACP/2020\%20AACP\%20Pharm.D.\%20Seats\%20Survey\% 20Report1.pdf?AWSAccessKeyId=AKIAVRDO7IEREB57R7MT\& Expires $=1601429055 \&$ Signature $=$ IvxhGtOgQd6VXuLW3RScyhVZ0fQ\% 3D. Accessed September 29, 2020.

8. American Association of Colleges of Pharmacy. 2019-20 Tuition and Fees at U.S. Colleges and Schools of Pharmacy. https://www. aacp.org/research/pharmd-and-graduate-programs-tuition-and-fees. Accessed September 29, 2020.

9. American Association of Colleges of Pharmacy. Graduating Student Survey 2019 National Summary Report. https:/www.aacp. org/sites/default/files/2019-07/2019-gss-national-summary-report_0. pdf. Accessed September 29, 2020.

10. Lebovitz L, Eddington ND. Trends in the pharmacist workforce and pharmacy education. Am J Pharm Educ. 2019;83(1):Article 7051. 


\section{American Journal of Pharmaceutical Education 2020; 84 (10) Article 8136.}

11. Maine L. It really isn't that simple. Am J Pharm Educ. 2019; 83(4):Article 7593.

12. American Association of Medical Colleges. U.S. Medical School Enrollment Rises 30\%. AAMCNEWS, July 15, 2019. https://www. aamc.org/news-insights/us-medical-school-enrollment-rises30\#: : text $=$ New\%20section,higher\%20than $\% 20$ in $\% 202002 \%$ 2D03. Accessed September 29, 2020.

13. American Association of Colleges of Osteopathic Medicine. Preliminary Enrollment Report Fall 2018. https://www.aacom.org/ docs/default-source/data-and-trends/preliminary-enrollment-reportfall-20180c104f43514d6e069d49ff00008852d2.pdf?sfvrsn= 54422197_8. Accessed September 29, 2020.

14. AACP. 2019-20 Profile of Pharmacy Faculty. https://www. aacp.org/research/institutional-research/pharmacy-facultydemographics-and-salaries. Accessed September 29, 2020. 15. Ford $\mathrm{H}$. An exploratory analysis of PharmD program value using the tuition:licensure index. Am J Pharm Educ. 2020;84(3):Article 847614 .

16. Williams JS, Spivey CA, Hagemann TM, Phelps SJ, Chisholm-Burns M. Impact of pharmacy school characteristics on
NAPLEX first-time pass rates. Am J Pharm Educ. 2019;83(6):Article 6875.

17. National Association of Boards of Pharmacy. Passing Rates for 2017-2019 Graduates Per Pharmacy School. https://nabp.pharmacy/ wp-content/uploads/2019/03/NAPLEX-Pass-Rates-2019.pdf.

Accessed September 29, 2020.

18. Bauman JL, Ascione FJ, Brueggemeier RW, et al. Maintaining pharmacy education's research focus as the academy expands. $A m J$ Pharm Educ. 2012;76(8):Article 144.

19. DiPiro J. The $21^{\text {st }}$ century Abraham Flexner. Am J Pharm Educ. 2008;72(4):Article 79.

20. Pavuluri N, Aparasu RR, Boje KMK, et al. Consideration of aggressive and strategic approaches to address declining enrollment in US pharmacy schools. Am J Pharm Educ. 2019;83(6): Article 6959.

21. Curtis S, Feild C, Buring SM. A task force on recruitment, admissions, and retention to improve pharmacy college admissions outcomes. Am J Pharm Educ. 2019;83(9):Article 7307.

22. Pharmacy is Right for Me. https://pharmacyforme.org/about-us/. Accessed September 29, 2020. 